Cite this: RSC Adv., 2014, 4, 25736

Received 18th April 2014 Accepted 29th May 2014

DOI: $10.1039 / \mathrm{c} 4 \mathrm{ra03537b}$

www.rsc.org/advances

\section{Methodology for quantitative determination of the carbohydrate composition of brown seaweeds (Laminariaceae)}

\begin{abstract}
D. Manns, ${ }^{a}$ A. L. Deutschle, ${ }^{\text {b }}$ B. Saake ${ }^{\text {c }}$ and A. S. Meyer ${ }^{\star a}$
The monosaccharide composition of four different samples of brown seaweeds Laminaria digitata and Saccharina latissima were compared by different high performance anion exchange chromatography (HPAEC) methods after different acid hydrolysis treatments or a cellulase treatment. A two-step treatment of $72 \%(\mathrm{w} / \mathrm{w}) \mathrm{H}_{2} \mathrm{SO}_{4}+4 \%(\mathrm{w} / \mathrm{w}) \mathrm{H}_{2} \mathrm{SO}_{4}$ performed best, but cellulase treatment released more glucose than acid treatments. HPAEC with pulsed amperometric detection (PAD) allowed quantification of all present neutral sugars and the sugar alcohol mannitol. Furthermore, the use of guluronic, glucuronic, and galacturonic acid as standards enabled quantification of the uronic acids. A complete map of amino acids, fatty compounds, minerals, and ash was also achieved. L. digitata and S. latissima harvested in Denmark April (Baltic Sea, 2012) were dominated by alginic acid and ash (each 30\% by weight $(\mathrm{w} / \mathrm{w})$ of the dry matter) and $10 \%(\mathrm{w} / \mathrm{w})$ protein. In contrast, the dominant compound of $L$. digitata harvested in August (North Sea, 2012) was glucose constituting 51\% w/w of the dry matter, and with $16 \% \mathrm{w} / \mathrm{w}$ alginic acid. Washing prior to analysis mainly removed salts.
\end{abstract}

\section{Introduction}

Recently, carbohydrates from brown macroalgae (brown seaweeds) have received increased attention, also in Europe, as a new biomass resource for biofuels and manufacture of highvalue carbohydrate products. ${ }^{\mathbf{1}, 2}$ However, the proper assessment of the potential of this new resource for biorefinery purposes requires fast and reliable characterization of the biomass, notably with respect to the carbohydrate composition.

Several extraction and determination methods for particular compounds have been developed but no methods exist for total quantification of the carbohydrate contents and carbohydrate composition of brown seaweeds.

The composition of polysaccharides in (fibrous) terrestrial plant materials is usually determined by measuring the monosaccharide release after acid hydrolysis. The optimal type of acid hydrolysis treatment depends on the type of plant material, and no universal method exists. For pectinaceous plant materials, rich in uronic acids, treatment with hydrochloric acid $(\mathrm{HCl})$ or trifluoroacetic acid (TFA) is usually favored, ${ }^{3,4}$ whereas for lignocellulosic biomass acid hydrolysis with sulfuric acid

${ }^{a}$ Center for BioProcess Engineering, Department of Chemical and Biochemical Engineering, Technical University of Denmark, Building 229, DK-2800 Kgs. Lyngby, Denmark.E-mail: am@kt.dtu.dk; Tel: +45 45252800

${ }^{b}$ Johann Heinrich von Thünen-Intitute, Institute of Wood Research, Leuschner Str. 91B, 21031 Hamburg, Germany

${ }^{c}$ Chemical Wood Technology, Dept. of Wood Science, University of Hamburg, Leuschner Str. 91B, 21031 Hamburg, Germany
$\left(\mathrm{H}_{2} \mathrm{SO}_{4}\right)$ is generally the norm..$^{5-7}$ Analogously, different chromatography quantification techniques have subsequently been employed to assess the composition of the constituent monosaccharides.

Brown seaweeds (Phaeophyceae) are highly heterogeneous in their carbohydrate composition and the polysaccharides differ profoundly from those in terrestrial plants. Brown seaweed biomass is mainly composed of $\beta$-linked polysaccharides of neutral sugars and uronic acids but also harbor the sugar alcohol mannitol and proteins along with high ash contents. In the relatively cold Northern hemisphere, such as the European, North American, and Canadian waters, the carbohydrate composition varies throughout the year, with maximum ash, protein, and matrix polysaccharides (alginate, fucoidan) contents at the beginning of the spring, when the reserve compounds mannitol and laminarin are at a minimum. In the autumn the reverse is the case. Additionally, the carbohydrate structures and composition vary with the species, age of the algae population, and geographical location., ${ }^{\mathbf{1 , 8}, 9}$

Laminarin is the principal and unique carbohydrate reserve substance of brown seaweeds. This polysaccharide mainly consists of a backbone of (insoluble) $\beta$-1,3-bonded glucopyranoses of which some carry $\beta-1,6$-branched glucose residues. A typical laminarin chain is presumed to be made up of approximately 25 units that may be terminated with the other reserve substrate D-mannitol (M-chains) or glucose (G-chains), which are found in different ratios at the reducing end..$^{9-11}$ Mannitol, the alcohol form of mannose, is the first product of photosynthesis in brown macroalgae. ${ }^{8,9}$ The amounts of laminarin and 
mannitol found in the most studied brown seaweed species Laminaria digitata and Saccharina latissima, both belonging to the Laminariaceae family, differ widely due to large seasonal variations. Hence, levels ranging from $0-33 \%$ by weight of the total dry matter $(\mathrm{w} / \mathrm{w})$ for laminarin and $2-20 \% \mathrm{w} / \mathrm{w}$ for mannitol have been reported depending on the harvest month. ${ }^{1,12}$

Alginic acid, or alginate, consists of 1,4-glycosidically linked $\alpha$-L-guluronic acid (G) and $\beta$-D-mannuronic acid (M) in varying proportions forming linear chains with $\mathrm{M} / \mathrm{G}$ ratio ranges of 1.2 to 2.1 and higher. Hence, alginic acid (alginate) does not designate one particular monosaccharide or one type of homopolysaccharide. The linear chains are made up of different blocks of guluronic and mannuronic acids, which are C-5 epimers. ${ }^{9}$ The blocks are referred to as MM blocks or GG blocks, but less crystalline MG blocks may also occur. Alginate is the salt of alginic acid and is soluble with monovalent ions, e.g. $\mathrm{K}^{+}$, $\mathrm{Na}^{+}$, and insoluble with di-/polyvalent ions (except $\mathrm{Mg}^{2+}$ ). In the presence of $\mathrm{Ca}^{2+}$ the $\mathrm{GG}$ blocks form ionic complexes to generate a stacked structure known as the "egg-box model", responsible for hard gel formation., ${ }^{9,13,14}$

Fucoidans constitute another unique type of brown seaweed polysaccharide. Primarily, fucoidans from the Laminariaceae are composed of a backbone of $\alpha$-1,3-linked-L-fucopyranose residues with sulfate substitutions at C-4 and occasionally at the C-2 position in addition to 2-O- $\alpha$-L-fucopyranosyl, other glycosyl such as galactose, and/or acetate substitutions. ${ }^{15,16}$ However, the chemical structures and abundance of the sulfated fucans making up fucoidan in brown seaweeds vary significantly. ${ }^{15}$ Alginate and fucoidan as matrix substances can be found at any time in the seaweeds of Laminariaceae, but their relative amounts vary with the season, for alginate the levels vary from 17 to $45 \%$, for fucoidan between 3 and $10 \%(\mathrm{w} / \mathrm{w}){ }^{12,17,18}$ However, exact determination is difficult due to high heterogeneity and the data also vary with the extraction method. Cellulose in brown seaweed has received less attention but has been mentioned in the literature as a structural monosaccharide present in minor amounts. ${ }^{919}$ Besides polysaccharides, minerals and proteins constitute a significant proportion of the dry weight of brown seaweeds, mineral levels ranging from 15 to $39 \% \mathrm{w} / \mathrm{w}$, and protein levels from 3 to $16 \% \mathrm{w} / \mathrm{w}$. On the contrary, lipids always make up only a smaller fraction (below $2 \% \mathrm{w} / \mathrm{w}$ ) in brown seaweeds. ${ }^{19,20}$ The significant differences in the bond types and the types of monomeric carbohydrate building blocks dominating in terrestrial plants and brown seaweeds, respectively, call for attention to both the acid hydrolysis and the quantitative chromatography methodology used for compositional carbohydrate analysis of brown seaweeds.
The primary objective of this study was to examine the influence of different biomass material hydrolysis treatments and compare different high performance chromatography carbohydrate determination methods (borate vs. alkaline $(\mathrm{NaOH})$ elution) in order to identify an optimal strategy for determination of all structural carbohydrate monomers from one hydrolysate of brown seaweed. Another objective was to assess the options for using cellulases for direct enzymatic glucose release from the structural laminarin in the brown seaweed. Different samples of $L$. digitata and $S$. latissima were used as raw materials for the study (Table 1).

\section{Experimental}

\subsection{Materials}

L. digitata and S. latissima were harvested in April 2012 from the Danish Baltic Sea and freeze-dried. Another harvest of L. digitata was obtained from the Danish North Sea coast late August 2012. One part of this latter material was washed successively four times with water to remove residual sand and salt. Another fraction remained untreated. Both the washed and the unwashed material were oven-dried at $40{ }^{\circ} \mathrm{C}$ until equilibrium moisture (Table 1). As a benchmark for the acid hydrolysis and carbohydrate analyses, hydrothermally pretreated barley straw fibers were used; the straw had been subjected to a triple heating treatment at $16 \% \mathrm{w} / \mathrm{w}$ dry matter $(\mathrm{DM}): 60^{\circ} \mathrm{C}, 15 \mathrm{~min}$; liquids removed; $180{ }^{\circ} \mathrm{C}, 10 \mathrm{~min}$; and finally $195{ }^{\circ} \mathrm{C}, 3 \mathrm{~min} .{ }^{21}$ The pretreated barley straw was frozen, then defrosted and oven-dried at $40{ }^{\circ} \mathrm{C}$ until equilibrium moisture before use. Before analysis the dried seaweed materials and the pretreated straw material were ground by vibrating disc milling to pass a $100 \mu \mathrm{m}$ sieve.

Chemicals. Boric acid, disodium tetraborate $\left(\mathrm{Na}_{2} \mathrm{~B}_{4} \mathrm{O}_{7}\right)$, perchloric acid $\left(\mathrm{HClO}_{4}\right)$, sulfamic acid, sulphuric acid $\left(\mathrm{H}_{2} \mathrm{SO}_{4}\right)$, trifluoroacetic acid (TFA), $m$-hydroxybiphenyl, dimethyl sulfoxide

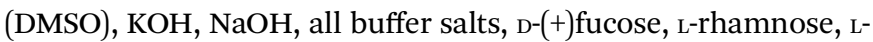
$(+)$ arabinose, D- $(+)$ galactose, D- $(+) x y l o s e, D^{-}(+)$mannose, D- $(+)$galacturonic acid, and D- $(+)$ glucuronic acid were from Sigma-Aldrich (Steinheim, Germany). Sodium acetate (NaOAc), D-mannitol, and 5-hydroxy-methyl furfural (5-HMF) were from Fluka/SigmaAldrich (Steinheim, Germany). Guluronic acid was purchased from Chemos GmbH (Regenstauf, Germany) and $\mathrm{D}-(+)$ glucose was from Merck (Darmstadt, Germany).

\subsection{Methods}

\section{Hydrolysis methods}

Sulfuric acid hydrolysis. A modified 2-step sulfuric acid hydrolysis of the NREL method ${ }^{7}$ was applied exposing the

Table 1 Overview of origin and preparation of the received brown seaweed samples and barley straw used in the present study

\begin{tabular}{ll} 
Sample & Origin/preparation \\
\hline L. digitata & April 2012 at Grenaa/Fornaes, Danish Baltic Sea coast (unwashed; freeze dried) \\
S. latissima & April 2012 at Grenaa/Fornaes, Danish Baltic Sea coast (unwashed; freeze dried) \\
L. digitata & End of August 2012 at Hanstholm, Danish North Sea coast (unwashed; oven dried) \\
L. digitata & End of August 2012 at Hanstholm, Danish North Sea coast (tap water washed to remove sand and salt; oven dried) \\
Barley straw & 2006 at Funen, Denmark (hot water extracted by Rosgaard et al. 2007; fibers separated from liquid; oven dried)
\end{tabular}


ground material (100 $\mathrm{mg}$ dry material per $\mathrm{mL}$ ) to $72 \% \mathrm{w} / \mathrm{w}$ $\mathrm{H}_{2} \mathrm{SO}_{4}$ at $30{ }^{\circ} \mathrm{C}$ for exactly $1 \mathrm{~h}$; the reaction mixture was then diluted for the $2^{\text {nd }}$ step to $4 \% \mathrm{w} / \mathrm{w} \mathrm{H}_{2} \mathrm{SO}_{4}$ and the hydrolysis continued for $40 \mathrm{~min}$ at $120{ }^{\circ} \mathrm{C}$ in an autoclave (method A). ${ }^{6} \mathrm{~A}$ milder $2^{\text {nd }}$ step adapted from Moxley and $\mathrm{Zhang}^{22}$ was performed using a $2 \% \mathrm{w} / \mathrm{w}$ solution of $\mathrm{H}_{2} \mathrm{SO}_{4}$ reacting for $30 \mathrm{~min}$ at $120{ }^{\circ} \mathrm{C}$ (method B). After hydrolysis, the hydrolysates were calibrated and filtered through a filter crucible (pore size 4; Schott, Germany).

Perchloric acid hydrolysis. A 2-step hydrolysis treatment was performed by adding $0.02 \mathrm{~mL} 70 \% \mathrm{w} / \mathrm{w} \mathrm{HClO}_{4}$ per $1 \mathrm{mg}$ of dry sample and allowing the hydrolysis to proceed for $10 \mathrm{~min}$ at room temperature. The hydrolysate was then diluted with 0.2 $\mathrm{mL}$ water and the second hydrolysis step was then done at $120{ }^{\circ} \mathrm{C}$ for $60 \mathrm{~min}$. After cooling, each sample was adjusted to neutral $\mathrm{pH}$ with $2 \mathrm{M} \mathrm{KOH}$. Precipitated $\mathrm{KClO}_{4}$ was separated by centrifugation. The supernatants were collected. ${ }^{23}$ The remaining precipitate was re-dissolved in hot water and then passed through a filter crucible (pore size 4).

Trifluoroacetic acid (TFA) hydrolysis. Samples were weighed into screw-cap vials and $2 \mathrm{M}$ TFA was added $(10 \mathrm{mg}$ dry material per $\mathrm{mL}$ ). Each vial was tightly sealed and heated at $121{ }^{\circ} \mathrm{C}$ for 2 h. Hydrolysates were lyophilized at $-20{ }^{\circ} \mathrm{C}$ under $\mathrm{N}_{2}$. Prior to chromatographic analysis the lyophilized samples were re-dissolved in deionized water, calibrated and filtered through a filter crucible (pore size 4; Schott, Germany). ${ }^{3}$ The acid-insoluble content, as well as the moisture content of all samples, were determined gravimetrically as the residue remaining after drying the filter crucibles at $103{ }^{\circ} \mathrm{C}$ overnight.

Enzymatic hydrolysis. The enzymatic treatment of the samples was conducted at $2 \%(\mathrm{w} / \mathrm{w})$ substrate concentration in $0.1 \mathrm{M}$ phosphate citrate buffer $\mathrm{pH} 5.1$ at $50{ }^{\circ} \mathrm{C}$ and treated with $20 \%$ Cellic®CTec2 (enzyme/substrate level in \% by weight). Cellic®CTec 2 is a commercially available cellulase preparation derived from Trichoderma reesei containing at least the two main cellobiohydrolases EC 3.2.1.91 (Cel6A and Cel7A), five different endo-1,4- $\beta$-glucanases EC 3.2.1.4 (Cel7B, Cel5A, Cel12A, Cel61A, and Cel45A), $\beta$-glucosidase EC 3.2.1.21, $\beta$ xylosidase EC 3.2.1.37, and particular proprietary hydrolysisboosting proteins (Novozymes A/S, Bagsværd, Denmark). The activity in filter paper units (FPU) of the enzyme preparation was $155 \mathrm{FPU} \mathrm{mL}^{-1}$. During the enzymatic hydrolysis samples were taken out at 2, 4, 6 and $24 \mathrm{~h}$. The reaction was stopped by mixing the sample with $5 \mathrm{M} \mathrm{NaOH}$.

Carbohydrate analysis. Monomeric sugars, 5-hydroxy-methylfurfural (5-HMF), sugar alcohol mannitol and uronic acids in the hydrolysates were separated by a Dionex ICS-3000 HPAEC-PAD on a Dionex CarboPac PA20 column using the three eluents: A deionized water, B $200 \mathrm{mM} \mathrm{NaOH}$ and C $1 \mathrm{M} \mathrm{NaOAc}$ in $200 \mathrm{mM}$ $\mathrm{NaOH}$, all $\mathrm{CO}_{2}$ free and dosed in \% volume/volume (v/v). Prior to analysis, the samples were filtered through a $0.2 \mu \mathrm{m}$ syringe tip filter and diluted appropriately in $200 \mathrm{mM} \mathrm{NaOH}$. Chromatographic elution was carried out at a flow rate of $0.4 \mathrm{~mL} \mathrm{~min} \mathrm{~m}^{-1}$ using B at 1\% in A for 25 min for separation of neutral sugars and sugar alcohol. Subsequently, separation of uronic acids was performed by a linear gradient from 3 to $50 \%$ B plus 3 to $20 \% \mathrm{C}$ in A for $20 \mathrm{~min}$ and completed with a linear gradient of $\mathrm{C}$ to $40 \%$ in
$60 \% \mathrm{~B}$ and A within $5 \mathrm{~min}$. The separated carbohydrates were detected using pulsed amperometric detection (PAD) with a gold working electrode. To increase the sensitivity of the detector after column addition of $200 \mathrm{mM} \mathrm{NaOH}$ was applied at a flow rate of $0.2 \mathrm{~mL} \mathrm{~min}^{-1}$ for the first $25 \mathrm{~min}$ and with a linear gradient down to $20 \mathrm{mM} \mathrm{NaOH}$ for the following $25 \mathrm{~min}$.

The contents of glucose, xylose and mannose in the hydrolysates were also analyzed by borate-anion-exchange-chromatography with post column derivatization and UV detection at $560 \mathrm{~nm}$ (HPAEC-Borate) as described in detail by Sinner et al. ${ }^{24}$ and Willfoer et al. ${ }^{5}$ For identification and quantification of the carbohydrates the Dionex software Chromeleon 6.80 was used.

Total uronic acids (UAs) in the hydrolysates were detected spectrophotometrically at $525 \mathrm{~nm}$ based on the method described by Filisetti-Cozzi and Carpita. ${ }^{25}$ Prior to the color reaction samples were filtered through a $0.2 \mu \mathrm{m}$ syringe filter and diluted appropriately in deionized water. Then $4 \mathrm{M}$ sulfamate (prepared after Filisetti-Cozzi and Carpita ${ }^{25}$ ) was added to the sample in proportion $1: 10$. The $\mathrm{H}_{2} \mathrm{SO}_{4}$ concentration was adjusted to $80 \% \mathrm{w} / \mathrm{w}$ by mixing the sample with $\mathrm{H}_{2} \mathrm{SO}_{4}$ (analytical grade) containing $120 \mathrm{mM} \mathrm{Na}_{2} \mathrm{~B}_{4} \mathrm{O}_{7}$. After adding the color reagent $m$-hydroxydiphenyl (prepared after van den Hoogen et $a l .{ }^{26}$ ) the absorbance, $525 \mathrm{~nm}$, was monitored for $20 \mathrm{~min}$ and the maximum was reported. Background absorbance was determined individually and subtracted before the UA content was determined as galacturonic acid (GalA) equivalents from the corresponding GalA reference curve. For estimation of the recovery factor (RF) GalA was treated according to the relevant sulfuric acid hydrolysis procedure and GalA was then quantified colorimetrically as described above.

Proximate, ultimate and metal analysis. $\mathrm{C}, \mathrm{H}, \mathrm{N}$ and $\mathrm{S}$ contents were measured by elemental analysis (vario EL cube, Elementar Hanau/Germany). The relative percentage of each was determined and the oxygen content was estimated as the difference and corrected for ash content. The ash contents were obtained and determined gravimetrically after low temperature oxidation $\left(550{ }^{\circ} \mathrm{C}\right)$ of the samples in a furnace. For metal analysis the samples were digested with concentrated $(65 \%) \mathrm{HNO}_{3}$ in a Milestone MLS Stat 1200 lab microwave and analyzed by inductively coupled plasma spectrometry (ICP) with mass spectrometric detection (Thermo Scientific iCAP 6300).

Analysis of amino acids and fatty compounds. Amino acid analyses (AAA) were performed according to Barkholt and Jensen. ${ }^{27}$ Extraction of fatty compounds was carried out with the solvent petrol in an ASE apparatus (Accelerated Solvent Extractor, Dionex Corp.) in two cycles at $70{ }^{\circ} \mathrm{C}$ and 100 bar. $^{28}$

FTIR spectroscopy. Residues from the 2-step sulfuric acid hydrolysis (method A) were measured on a Bruker Vector 33 FTIR-spectrometer. The spectra were recorded between 3750 and $583 \mathrm{~cm}^{-1}$ on a DTGS detector using attenuated total reflection; resolution $4 \mathrm{~cm}^{-1}$; 60 scans; analysis software OPUS 6.5 (Bruker, Germany). ${ }^{29}$

\subsection{Statistics}

One-way analyses of variances (one-way ANOVA): 95\% confidence intervals were compared as Tukey-Kramer intervals 
calculated from pooled standard deviations (Minitab Statistical Software, Addison-Wesley, Reading, MA).

\section{Results and discussion}

\subsection{Monomeric carbohydrate yields from the decomposition techniques}

Different plant polysaccharide acid hydrolysis methods for obtaining monomeric carbohydrates were investigated. Primarily, the employment of trifluoroacetic acid (TFA) hydrolysis $\left(121^{\circ} \mathrm{C}, 2 \mathrm{~h}\right)$ was inefficient on the brown seaweed samples (only April samples tested) and left behind a significant amount of residue making up approx. $30 \%$ by weight of the dry raw material weight (data not shown). In comparison, the amount of unhydrolysed residue on the same samples constituted $\sim 5-10 \%$ $\mathrm{w} / \mathrm{w}$ after the perchloric or the sulfuric acid hydrolysis treatments (Table 2). The amounts of hydrolysis residues obtained after perchloric acid hydrolysis on the seaweed were generally a little higher than those obtained for both sulfuric acid hydrolysis methods (Table 2). For the barley straw, the residue after perchloric acid was $41.6 \% \mathrm{w} / \mathrm{w}$ as opposed to that of $\sim 30 \% \mathrm{w} / \mathrm{w}$ (also known as Klason Lignin) obtained after the sulfuric acid hydrolyses. Significantly lower monomeric carbohydrate yields, glucose, fucose and uronic acids, were obtained with the perchloric acid as compared to the strong acid hydrolysis, especially for the April harvested samples (Table 2). Determination of the fucose levels was less affected by the type of acid treatment, but as expected, the fucose levels tended to be higher in the samples harvested in the spring than in August ( $L$. digitata Apr'12 vs. Aug'12, Table 2). The levels for mannitol were in the same range of 4 to $10 \% \mathrm{w} / \mathrm{w}$ for all brown seaweed samples after acid treatment, but the values tended, as expected, to be higher in the samples harvested in August (Table 2). Ostgaard et al..$^{30}$ measured mannitol directly in the supernatant of thawed S. latissima and found mannitol contents of $4 \%$ for spring and $16 \%$ for autumn respectively. Adams et al. ${ }^{1}$ used a $5 \mathrm{mM}$ sulfuric acid hydrolysis on ground $L$. digitata and also observed a seasonal variation of the mannitol ranging from a minimum of $5 \% \mathrm{w} / \mathrm{w}$ in the beginning of the year to a peak in June before the mannitol levels determined remained constant between 15 and $20 \% \mathrm{w} / \mathrm{w}$.

Perchloric acid hydrolysis was demonstrated to give high glucose yields when applied on the highly polymerized substrate carboxy-methyl-cellulose. ${ }^{23}$ Glucose levels determined for $L$. digitata and $S$. latissima from the April harvest, were significantly lower after $\mathrm{HClO}_{4}$ treatment than after sulfuric acid hydrolysis, e.g. for $S$. latissima only $0.9 \% \mathrm{w} / \mathrm{w}$ compared to 4.6 and $6.8 \% \mathrm{w} / \mathrm{w}$, respectively were recovered (HPAEC-PAD data, Table 2). A similar trend was observed for the glucose determined after acid hydrolysis on the pretreated straw (Table 2). Sulfuric acid hydrolysis performed by Ostgaard et $a l^{30}$ on Laminaria saccharina (now classified as Saccharina latissima) gave glucose concentrations, accounted for as laminarin, that were below $1 \% \mathrm{w} / \mathrm{w}$ for seaweed samples harvested in the spring, but $20 \% \mathrm{w} / \mathrm{w}$ for samples harvested in the autumn.

All acid hydrolysates were checked for 5-HMF as a degradation product of hexoses. ${ }^{6} 5$-HMF was not detected in any of the mildly treated sulfuric acid samples, i.e. with method B (except for the pretreated straw; $2 \mathrm{mg}$ 5-HMF per g biomass). However, in the stronger sulfuric acid hydrolysates (method A) as well as after the $\mathrm{HClO}_{4}$ treatment, 5-HMF was present in the samples having high glucose content, but only in minor amounts of $<5 \mathrm{mg}$ per $\mathrm{g}$ biomass (data not shown). Low contents of degradation products and hydrolysis residues indicated appropriate acid hydrolysis conditions for the decomposition of brown seaweed carbohydrates into monomers. Residues of the sulfuric acid hydrolysis (method A) were analyzed by FTIR, and this analysis indicated the presence of a variety of reaction products from the different polymers (data not shown). Elemental analysis revealed $\mathrm{N}$ contents below $3 \%$ by weight, very low contents of sulfur and $40-50 \%$ of C based on dry residues. Potentially, hydrolysis residues consist of condensed proteins, inorganic compounds and insoluble polysaccharides from incomplete hydrolysis, in particular alginic acid. Overall, the amounts of residue correlated with the ash content for all seaweed samples, but the amounts of residue were below $10 \%$ by weight of dry algae for all hydrolysis methods (Table 2).

Sulfuric acid hydrolysis with post-hydrolysis at $4 \% \mathrm{H}_{2} \mathrm{SO}_{4}$ (method A) is widely used for lignocellulosic biomass analysis, and the method resembles the protocol recommended by the US National Renewable Laboratory (NREL) for acid hydrolysis of lignocellulosic feedstocks ${ }^{7}$ - except that in NREL's protocol the second step includes autoclave heating for $60 \mathrm{~min}$, not $40 \mathrm{~min}$. Surprisingly, the highest monosaccharide levels of brown seaweed were generally achieved with $\mathrm{H}_{2} \mathrm{SO}_{4}$ hydrolysis (method A), notably with regard to the detection of uronic acids (UA), presumed to be mainly derived from alginate, as the uronic acid yields were significantly above those obtained with the other hydrolysis methods (Table 2). This finding was in accord with what was reported early by Percival and McDowell, ${ }^{9}$ namely, that polysaccharides containing high levels of uronic acids like alginic acid, need drastic hydrolysis conditions to achieve a satisfactory decomposition into their carbohydrate monomers. The data obtained for uronic acids (Table 2) reflected the expected amount of alginic acid. Hence, the reported values for alginic acid content in $L$. digitata range from 17 to $44 \%$ by weight correlating with the seasonal variation - the highest levels are generally found in samples harvested winter/ early-spring, whereas the lowest levels are found in samples harvested late summer/early autumn. ${ }^{1,31}$ Uronic acids are discussed further in Section 3.2.

Additionally, the available glucans were enzymatically cleaved using the commercial enzyme preparation Cellic ${ }^{\circledR C}$ Tec2 (Novozymes, Denmark). For the L. digitata samples harvested in August, high levels of hydrated glucose of 64 to $77 \%$ by weight were released by the enzymatic treatment within $6 \mathrm{~h}$, and no further increase was noted. The HPAEC-PAD results for enzymatic glucose liberation from the April L. digitata harvest stayed constant at $10.7 \%$ already after $2 \mathrm{~h}$ of hydrolysis, whereas for the pretreated straw, the glucose yield increased over the whole duration of $24 \mathrm{~h}$ during the enzymatic treatment without releasing all potential monomeric glucose (Table 2). Adams et al. ${ }^{1}$ used laminarinases, active only on $\beta-1,3$ glucan, to estimate the concentration of laminarin dependence on the season 


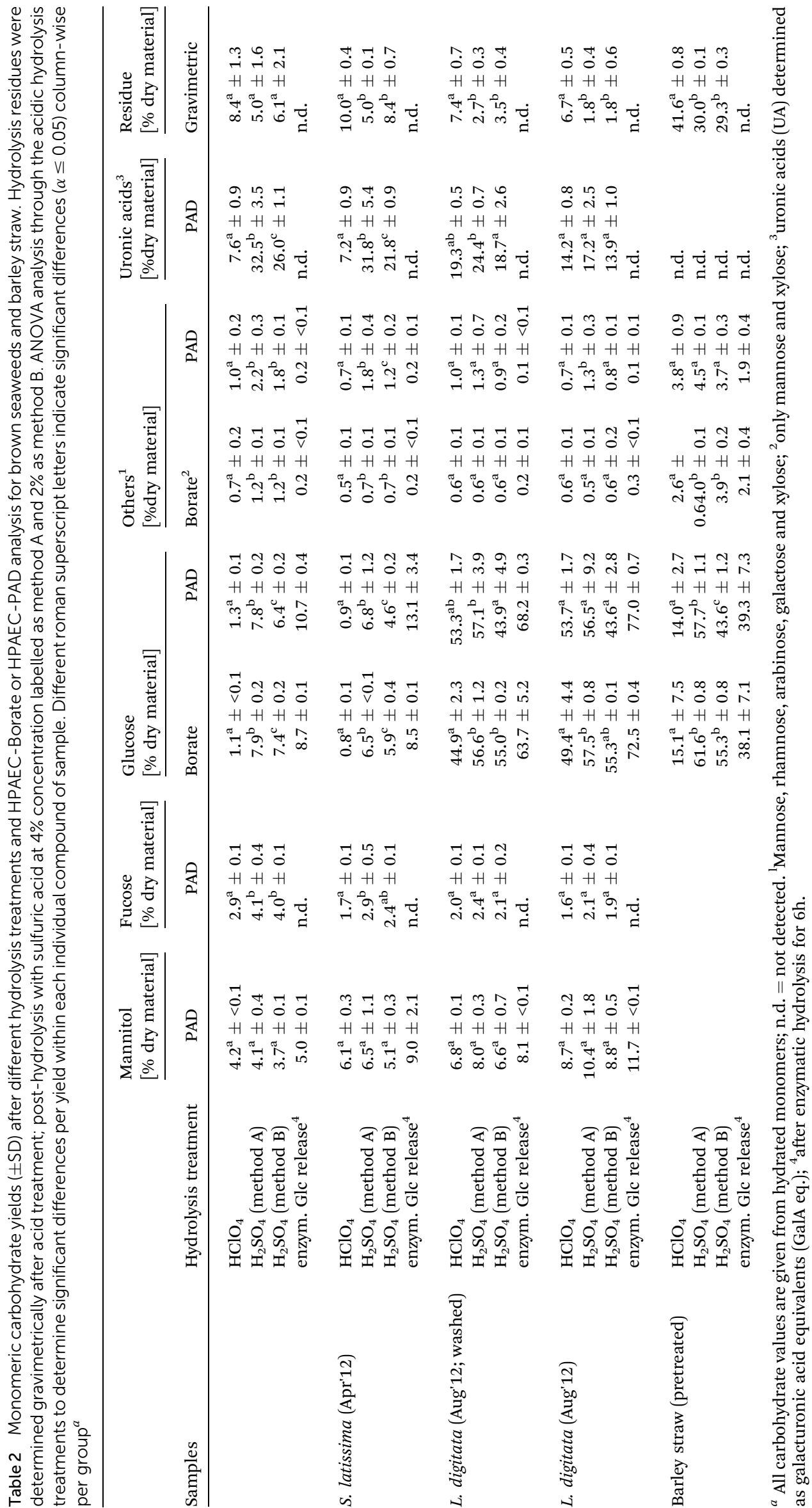


for $L$. digitata. However, the data obtained by the use of a high dosage of the Cellic®CTec 2 showed that the enzymatically released glucose levels were consistently higher than those obtained by any of the sulfuric acid hydrolysis methods or the $\mathrm{HClO}_{4}$ method. The cellulase treatment thus catalyzed the decomposition of the glucose containing polysaccharides in the seaweed, and also efficiently catalyzed mannitol liberation (Table 2). No alginate degradation took place during cellulase treatment (the levels of uronic acids were nil), and cellulase treatment also released lower yields of other monomeric carbohydrates than the chemical hydrolysis methods (Table 2).

HPAEC-borate has been established as an optimal analytical method for analysis of lignocellulosic carbohydrates. ${ }^{\mathbf{5 2 4}}$ For separation of common compounds in acid hydrolysates of brown seaweed, glucose, xylose and mannose, this chromatography method produced highly reproducible results (Table 2). However, it was only possible to detect all carbohydrates especially sugar alcohols and uronic acids by HPAEC-PAD (Table 2).

\subsection{Uronic acids}

Uronic acids (UA) of brown seaweed can be separated and electrochemically quantified by HPAEC-PAD (Table 3). Small amounts of glucuronic acid, below $2 \% \mathrm{w} / \mathrm{w}$ in each sample, were determined in all the brown seaweed samples (Table 3). The detection of glucuronic acid was in agreement with what was reported in an early study by Knutson and Jeanes. ${ }^{32}$

Furthermore, guluronic acid was identified and quantified, but galacturonic acid was not found in any of the seaweed samples. Mannuronic acid (M) in its monomeric form is only available commercially as the lactone of mannuronic acid. Hence, mannuronic acid was quantified as galacturonic acid equivalents, but was found to be the dominant uronic acid in the brown seaweed samples (Table 3).

According to the literature $\mathrm{M} / \mathrm{G}$ ratios depend on seaweed species but also vary within the different species. For L digitata and $S$. latissima $\mathrm{M} / \mathrm{G}$ ratios from 1.1 to 2.1 and up to 3.1 have been reported. ${ }^{9,32}$ The $\mathrm{M} / \mathrm{G}$ ratio for the $L$. digitata seaweed harvested in April 2012 from the Danish Baltic Sea was 2.0, for S. latissima it was 2.4, but ratios were higher (2.8-3.0) for the samples harvested from the North Sea in late summer 2012 (Table 3). Quantification of mannuronic acid (ManA) as galacturonic acid (GalA) equivalents and summation of the values with guluronic acid (GulA) as alginic acid led to estimated levels of about $32-33 \% \mathrm{w} / \mathrm{w}$ alginate in the seaweed samples harvested early spring versus $\sim 20 \% \mathrm{w} / \mathrm{w}$ alginate in the samples harvested late summer (Table 3). The different fractions of alginic acid MM, GG, GM and MG blocks depolymerize at different rates in response to acid treatment, ${ }^{9}$ and GulA has a relatively high acid lability. ${ }^{32}$ Nevertheless, despite the uncertainties regarding the application of GalA as a standard for ManA and monomer recovery, the total amounts of the individually quantified uronic acids (Table 3) reflected those reported previously in the literature. Moreover, the response factor of ManA for HPAEC analysis can tentatively be concluded to be similar to the response of GalA and likely between that of glucuronic and guluronic acid. In this regard, the application of the present method also provides a reasonably reliable option for presenting all uronic acids directly as GalA equivalents probably because the response factor of GalA is close to that of the dominant uronic acid. Values were in the same range as the total of all individual monomers, but only when expressed as GalA equivalents (Table 3).

Filisetti-Cozzi and Carpita ${ }^{25}$ recommend the measurement of total uronic acids as GalA equivalents by colorimetric analysis with the absorption of GalA being close to that of ManA after addition of $120 \mathrm{mM}$ tetraborate to the reaction. However, Percival and $\mathrm{McDowell}^{9}$ noted an influence of the $\mathrm{M} / \mathrm{G}$ ratio on the absorbance. In this colorimetric method uronic acids react with concentrated sulfuric acid producing 5-formyl-2-furancarboxylic acid (5FF) which, in the absence of water, further reacts with 3-phenylphenol to produce a colored red-pink chromogen. ${ }^{33}$ In the present work, yields quantified in galacturonic acid equivalents for total uronic acids only gave half of the amount of uronic acids as the HPAEC-PAD analysis on the same sulfuric acid hydrolysate (Table 3). The values were nevertheless in agreement with those reported previously for $S$. latissima ${ }^{30}$ where low contents of total uronic acids of $15 \%$ and $23 \%$ in the spring were noted by use of a similar method. Spectrophotometric determination of alginic acid after $\mathrm{HCl}$ treatment gave slightly higher quantities of 20 to $30 \%,{ }^{31}$ whereas Rioux et al., ${ }^{34}$ by use of the 3-phenylphenol method, reported total uronic acids mostly being below $10 \% \mathrm{w} / \mathrm{w}$ for different brown seaweeds.

Table 3 From left to right: yields ( \pm SD) of individual determined monomeric uronic acids (UA) and ratio of mannuronic acid to guluronic acid after pre-treatment with $72 \% \mathrm{H}_{2} \mathrm{SO}_{4}, 4 \%$ post-hydrolysis and subsequent HPAEC-PAD analysis; determined as total UA displayed as equivalents (eq.) after HPAEC-PAD or colorimetric analysis out of the same hydrolysates; and corrected with recovery factor for colorimetric measurement ${ }^{a}$

\begin{tabular}{|c|c|c|c|c|c|c|c|c|c|c|}
\hline \multirow[b]{2}{*}{ Sample } & \multicolumn{5}{|c|}{ UA monomers by HPAEC ${ }^{1}$} & \multicolumn{3}{|c|}{ Total UA by HPAEC ${ }^{1}$ as equivalents } & \multicolumn{2}{|c|}{ Total UA by UV } \\
\hline & $\begin{array}{l}\text { GulA } \\
{[\%]}\end{array}$ & $\begin{array}{l}\text { GluA } \\
{[\%]}\end{array}$ & $\operatorname{ManA}[\%]^{2}$ & $\begin{array}{l}\text { Total } \\
{[\%]}\end{array}$ & $\mathrm{M} / \mathrm{G}^{3}[-]$ & $\begin{array}{l}\text { GalAeq } \\
{[\%]}\end{array}$ & $\begin{array}{l}\text { GluAeq } \\
{[\%]}\end{array}$ & $\begin{array}{l}\text { GulAeq } \\
{[\%]}\end{array}$ & $\begin{array}{l}\text { GalAeq } \\
{[\%]}\end{array}$ & $\begin{array}{l}\text { GalAeq } \mathrm{RF}^{4} \\
{[\%]}\end{array}$ \\
\hline L. digitata (Apr'12) & $10.4 \pm 1.1$ & $1.7 \pm 0.2$ & $20.6 \pm 2.2$ & $32.7 \pm 3.5$ & $1.99 \pm 0.04$ & $32.5 \pm 3.5$ & $20.3 \pm 2.2$ & $38.8 \pm 4.2$ & $17.2 \pm 1.4$ & $28.0 \pm 2.3$ \\
\hline S. latissima (Apr'12) & $9.0 \pm 1.6$ & $1.4 \pm 0.2$ & $21.4 \pm 3.6$ & $31.8 \pm 5.4$ & $2.41 \pm 0.04$ & $31.8 \pm 5.4$ & $19.9 \pm 3.4$ & $38.0 \pm 6.5$ & $15.3 \pm 3.6$ & $24.9 \pm 5.9$ \\
\hline $\begin{array}{l}\text { L. digitata (Aug'12; } \\
\text { washed) }\end{array}$ & $5.7 \pm<0.1$ & $1.0 \pm<0.1$ & $17.2 \pm 0.6$ & $23.9 \pm 0.8$ & $3.00 \pm 0.09$ & $24.4 \pm 0.7$ & $15.2 \pm 0.4$ & $29.1 \pm 0.8$ & $10.3 \pm 6.5$ & $16.7 \pm 10.6$ \\
\hline L. digitata (Aug'12) & $4.5 \pm 0.7$ & $0.7 \pm 0.1$ & $12.2 \pm 1.8$ & $17.4 \pm 2.6$ & $2.81 \pm 0.06$ & $17.2 \pm 2.5$ & $10.8 \pm 1.5$ & $20.6 \pm 2.9$ & $8.7 \pm 2.9$ & $14.2 \pm 4.8$ \\
\hline
\end{tabular}

${ }^{a} \mathrm{Gu} 1 \mathrm{~A}=$ guluronic acid; G1uA = glucuronic acid; ManA = mannuronic acid; GalA = galacturonic acid; eq. $=$ equivalent. ${ }^{1} \mathrm{All}$ values are given from hydrated monomers; ${ }^{2}$ given as GalA equivalents; ${ }^{3}$ ratio of ManA (M) to GulA (G); ${ }^{4}$ recovery factor (RF) $61.4 \pm 5.9[\%]$. 
HPAEC-PAD measurement is principally superior to the chromogenic measurement of total uronic acids, since the HPAEC assesses the actual individual monomer(s) and not the reactivity of a degradation product. Potentially, the gap between the methods may be due to the formation of further degradation products during the recurrent exposure of the hydrolysate to strong acid during preparation of the colorimetric measurement. An assessment of the recovery factor for galacturonic acid was performed along the sample chronology. For the first two step sulfuric acid hydrolysis (method A), a recovery of $57.0 \pm$ $3.0 \%$ of galacturonic acid was achieved by HPAEC-PAD analysis. The overall recovery including the preparation for UVmeasurement with $80 \%$ sulfuric acid was $61.4 \pm 5.9 \%$ of the $5 \mathrm{FF}$-chromogen by colorimetric analysis. This factor was applied and found to be more in agreement with the results of the HPAEC measurements (Table 3). However, application of the $57 \%$ as recovery factor for galacturonic acid to the HPAEC results produced a too high recovery in relation to the overall mass balances. An independent second determination for the recovery of galacturonic acid after 2-step sulfuric acid hydrolysis gave a recovery of only $\sim 42 \%$ which further challenges the applicability of recovery factors for determination of uronic acid based polysaccharides ${ }^{5,6}$. Hence, determination of recovery factors by exposing monomers, particularly uronic acids, to the same acid hydrolysis conditions as the sample containing the hetero-polymeric polysaccharides appears error-prone due to different degradation behaviors.

\subsection{Amino acids, fats, minerals and ash}

Generally, brown seaweed contains significantly more protein than lignocellulosic biomass, but variations in the amounts and the amino acid composition are significant. L. digitata and $S$. latissima from April contained about $9 \%$ and $10 \%$ by weight of amino acids, respectively (Table 4), whereas $L$. digitata from August only contained about $3 \% \mathrm{w} / \mathrm{w}$ and the pretreated straw only of $0.4 \% \mathrm{w} / \mathrm{w}$ (Tables 4 and 7 in the Appendix). The protein content is known to range from $3-21 \%$ by weight for $L$. digitata and $S$. latissima ${ }^{12,20}$ the difference in the levels being due to the source and harvest season but also affected by the application of different nitrogen-to-protein factors, the most commonly used being 6.25. Lourenco et al. ${ }^{35}$ collected seaweed (although not $L$. digitata or $S$. latissima) along the Brazilian coast line and found $75-99 \%$ of $\mathrm{N}$ related to protein with a factor of $5.38 \pm 0.5$, amino

Table 4 Total of amino acids (AA) after amino acid analysis ( $\pm S D$ ), nitrogen $(N)$ content determined by elemental analysis $( \pm S D)$ and $N$ to-protein factor (AA divided by $\mathrm{N}$ ) for brown seaweed samples and the overall average. (For complete amino acid analysis see Table 7 in Appendix)

\begin{tabular}{lcll}
\hline & AA & N & \\
Sample & {$[\%$ dry material] } & $\begin{array}{l}\text { factor } \\
\text { N-to-protein }\end{array}$ \\
\hline L. digitata (Apr'12) & $9.3 \pm 0.4$ & $2.7 \pm<0.1$ & $3.44 \pm 0.13$ \\
S. latissima (Apr'12) & $10.1 \pm 0.1$ & $2.6 \pm<0.1$ & $3.83 \pm 0.04$ \\
L. digitata (Aug'12; washed) & $3.2 \pm 0.4$ & $0.7 \pm<0.1$ & $4.34 \pm 0.61$ \\
Average & 6.4 & 1.7 & 4.02
\end{tabular}

acid residues divided by nitrogen, for brown seaweed. By dividing the total amino acids by nitrogen content $L$. digitata revealed an N-to-protein ratio of 3.4 for the April harvest and 4.4 for the August harvest, and the ratio for $S$. latissima was found to be 3.8 (Table 4). This indicates that application of nitrogen-toprotein factors should be used carefully in order to avoid a potential risk of overestimation. Oppositely, the degradation of proteins during acid hydrolysis, considered to be $5-10 \%$ of most of amino acids, could also be taken into account. ${ }^{27}$

Fatty compounds were quantified gravimetrically with maximum amounts of $1 \%$ by weight after extraction with petrol and the levels were in accordance to the literature. ${ }^{12}$ Ash content and mineral composition differed highly from terrestrial plants and varied with the harvest time (Tables 5 and 8 in Appendix). In general, the brown seaweeds have higher ash contents than other seaweed types. ${ }^{36}$ A significantly low content of approx. 3\% ash and $0.4 \% \mathrm{w} / \mathrm{w}$ minerals was found for the straw sample compared to the brown algae. Seaweeds from April contained more than $6 \%$ by weight of minerals and had an ash content of over $30 \% \mathrm{w} / \mathrm{w}$ (Table 5). In contrast, when carbohydrate contents of glucose and mannitol were high, L. digitata contained only $11.9 \% \mathrm{w} / \mathrm{w}$ of ash (Table 5 ), a level similar to that reported by Adams et al. ${ }^{1}$ By applying washing as pretreatment the ash content was lowered to $7.9 \%$ and the mineral content to $2 \% \mathrm{w} / \mathrm{w}$ (Table 5 ). The lower level of minerals after washing was primarily due to the removal of sodium and potassium as salts by the washing. Together with sodium and potassium, calcium, phosphorus, and sulfur are the major minerals in brown seaweed.

For $L$. digitata Ruperez ${ }^{36}$ found an ash content of $37 \%$ and total cations of $17 \%$ by weight. Ross et al. ${ }^{37}$ noted ash contents of $11 \%$ to $38 \% \mathrm{w} / \mathrm{w}$ along with 6 to $15 \%$ minerals and up to 11 $\mathrm{mol} \mathrm{g}^{-1}$ of halogens for different brown seaweeds (L. digitata: $25.8 \%$ ash and $11.3 \%$ minerals). Adams et al. ${ }^{1}$ studied the seasonal variation of $L$. digitata and found total metal content in samples harvested in April of $13.7 \%$ and about $7 \%$ for samples collected in August and September. Seaweed ash is known to contain carbonates and sulfates. ${ }^{36}$ The contents of carbonates and sulfates may partly explain the discrepancy between the total of ICP tracked minerals and determination of the ash content, not considering the amount of halogens like iodine and chlorine. The high discrepancy in mineral contents to the literature derived mainly from the concentration of $\mathrm{Na}$, where analyzed $L$. digitata gave low contents of maximum 10000 ppm.

Table 5 Total of minerals after ICP-MS $( \pm S D)$ and ash content after incineration $( \pm S D)$ for brown seaweeds and barley straw. (For complete mineral analysis see Table 8 in Appendix)

\begin{tabular}{llc}
\hline Sample & Minerals [\%] & Ash [\%] \\
\hline L. digitata (Apr'12) & $6.2 \pm 0.1$ & $31.0 \pm 0.1$ \\
S. latissima (Apr'12) & $6.4 \pm 0.1$ & $34.6 \pm 0.2$ \\
L. digitata (Aug'12; washed) & $2.0 \pm<0.1$ & $7.9 \pm 0.1$ \\
L. digitata (Aug'12) & $2.9 \pm<0.1$ & $11.9 \pm 0.1$ \\
Barley straw (pretreated) & $0.4 \pm 0.1$ & $2.8 \pm 0.2$
\end{tabular}




\subsection{Overall map of compounds}

Additional determination of total amino acid and fats to carbohydrate analysis allowed quantification of total organic matter (TOM). For both April harvested L. digitata and S. latissima Table 6 accounts about 56\% for TOM with only minor differences along protein and dehydrated monomeric carbohydrate composition. Hence, L. digitata from August consisted of about $84 \%$ TOM, about $30 \%$ more compounds of organic matter compared to April's L. digitata. This was primarily due to the extremely change in the glucose content to $51 \%$ which was dominant in this sample. In April the most dominant organic compounds were the uronic acids. The uronic acids constituted about $30 \%$, mainly derived from the alginic acid, but also the level of proteins was higher in April. The difference of measurements of all neutral sugars, mannitol, proteins and fats as total organic matter to determination of $\mathrm{C}, \mathrm{H}, \mathrm{N}$ and $\mathrm{O}$ detected by elemental analysis (Table 6) was calculated as the theoretical amount of uronic acids. For the early spring harvested samples, the calculated averages were found to be slightly elevated as compared to those from August, 39.1\% vs. $32.7 \%$ for $L$. digitata and $35.4 \%$ vs. $31.8 \%$ for $S$. latissima. In general, taking the standard deviations into account, all HPAEC-PAD measurements agreed satisfactorily with the theoretical calculations.

As stated above, washing mainly affected the ash content but also mannitol appeared to be washed out. Overall, the relative proportion of organic matter compounds increased from about 84 to $89 \%$ even though the mannitol level decreased from 10.4 to $8 \%$ (Table 6).

By summing up the overall map of compounds, the recovery added up to about $90 \%$ for all samples by the addition of the ash content to the TOM (Table 6). The difference to a fulfilled composition (of $100 \%$ ) can probably be found in the heterogeneous hydrolysis residues. For straw this difference was accounted for as lignin, but the nature of the remaining mass is uncertain for seaweed. On the other hand, inaccuracies due to application of four different methods - carbohydrate analysis, amino acid analysis, quantification of fatty compounds and incineration - including their losses should be kept in mind. In particular, the values for total organic matter (TOM) are below estimation of CHNO by elemental analysis. For seaweed samples from April only 56\% of the TOM were estimated as compared to $67.3 \%$ to of $\mathrm{C}, \mathrm{H}, \mathrm{N}$ and $\mathrm{O}$ after elemental analysis, respectively $64 \%$ for $S$. latissima, whereas estimation for TOM of L. digitata from August was close to CHNO analysis. The values of individually determined TOM were only about 3\% below the sum of elements of $87 \%$, and $91 \%$, respectively for the washed seaweed (Table 6).

However, taking standard deviations into account the total of individually determined organic matters of all samples agreed well with the sum of the elementals CHNO (Table 6) which does not specify the origin of the carbon. Adams et al. ${ }^{1}$ found CHNO contents of $L$. digitata with less seasonal variation between 66 and $83 \%$ along with a maximum of $25 \%$ glucose determined as laminarin. Ostgaard et $a l^{30}$ similarly found less seasonal deviation for total organic matter. Like the results for April collected 
seaweed their compositions for spring harvested $S$. latissima were dominated by ash and alginate. In contrast, the dry matter composition of samples in autumn was almost equally distributed between ashes, laminarin, mannitol and alginate. However, not all organic matter could be identified. Rioux et $a l .{ }^{34}$ analyzed all compounds from brown seaweed. A sum-up of all extracted fractions of carbohydrate including proteins and lipids leads to a maximum yield of $2 / 3$ of what was expected as carbohydrates by difference of ash, proteins and lipids. However, even if uncertainties probably derived from the carbohydrate analysis remain by adding the ash the balance was acceptable for all brown seaweed samples and the benchmark data for straw (Table 6).

\section{Conclusions}

HPAEC-PAD analysis after a 2-step treatment with first $72 \%$ sulfuric acid for $1 \mathrm{~h}$ at $30{ }^{\circ} \mathrm{C}$ and then $4 \%$ at $120{ }^{\circ} \mathrm{C}$ for $40 \mathrm{~min}$ turned out to be the best methodology for quantitative determination of the brown seaweed carbohydrate composition. The high heterogeneity in the type of monomeric compounds and the high amounts of $\beta$-bonds in the polysaccharides in the brown seaweed along with high ion load challenged the analysis and could cause elevated deviations compared to lignocellulosic material. In contrast to the underestimating colorimetric measurements of total uronic acids the HPAEC-PAD analysis of the total individually measured uronic acids reflected the expected values. Furthermore, additional measurements for amino acids and fats the matter of total organic compounds was determined and successfully cross-verified with the sum of $\mathrm{C}, \mathrm{H}$, $\mathrm{N}$ and $\mathrm{O}$ as total organic compounds received from elemental analysis. Thereby, a full map of brown seaweed compounds was achieved. In contrast to pulsed amperometric detection (HPAEC-PAD), HPAEC-borate is an accurate and highly reproducible method but only detects glucose, xylose and mannose monomers. HPAEC analysis of enzymatically decomposed seaweed with a commercial enzyme solution revealed higher glucose yields as compared to all acid treatments for all the seaweed samples. Nevertheless, decomposition was incomplete as almost only glucose and mannitol were released.

The brown seaweeds Laminaria digitata and Saccharina latissima collected in April in the Danish Baltic Sea showed only minor differences in their composition. L. digitata harvested in August in the Danish North Sea had a total of organic matter (TOM) of $84 \%$ dominated by glucose $(51 \% \mathrm{w} / \mathrm{w})$ and therefore predestinated for $e . g$. biofuels. In the samples harvested in April the content of alginic acid and ash dominated where changes in the $\mathrm{M} / \mathrm{G}$ ratio from 2 in April to 2.8 in August also indicate different structures in the composition of alginic acid (although it cannot be ruled out that some of the differences were also caused by geographical differences). Total amino acid content of $3 \%$ in August is low compared to $10 \%$ present in April. In contrast, the N-to-protein factor was higher in August. Addition of the ash content to the TOM completes the mass balance. With the optimal 2-step sulfuric acid hydrolysis followed by HPAEC-PAD analysis a procedure for obtaining the full monomeric composition of neutral sugars, the sugar alcohol mannitol, and the uronic acids, where mannuronic acid was quantified as galacturonic acid equivalents, was achieved. Overall, a conclusive map of compounds for all brown seaweed samples was thus obtained.

\section{Appendix}

\section{Acknowledgements}

This work was supported by the Danish Council for Strategic Research via the MacroAlgaeBiorefinery (MAB3) project. The authors acknowledge Dr Annette Bruhn and Dr Michael Bo

Table 7 Amino acid (AA) composition after amino acid analysis ( \pm SD) for brown seaweed and barley straw (additional information to Table 4)

\begin{tabular}{|c|c|c|c|c|c|}
\hline & L. digitata (Apr'12) & S. latissima (Apr'12) & L. digitata (Aug'12; washed) & L. digitata (Aug'12) & Barley straw (pretreated) \\
\hline Amino acid & AA/biomass $\left[\mu \mathrm{g} \mathrm{mg}^{-1}\right]$ & AA/biomass $\left[\mu \mathrm{g} \mathrm{mg}^{-1}\right]$ & AA/biomass $\left[\mu \mathrm{g} \mathrm{mg}^{-1}\right]$ & AA/biomass $\left[\mu \mathrm{g} \mathrm{mg}^{-1}\right]$ & AA/biomass $\left[\mu \mathrm{g} \mathrm{mg}^{-1}\right]$ \\
\hline Total & $93.3 \pm 3.7$ & $101.0 \pm 1.0$ & $31.7 \pm 4.5$ & $31.3 \pm 2.4$ & $3.8 \pm 0.1$ \\
\hline Asp & $12.6 \pm 0.4$ & $12.8 \pm 0.3$ & $3.7 \pm 0.5$ & $3.2 \pm 0.1$ & $0.4 \pm<0.1$ \\
\hline Thr & $5.1 \pm 0.2$ & $5.2 \pm 0.4$ & $1.8 \pm 0.3$ & $1.3 \pm 0.1$ & $0.4 \pm<0.1$ \\
\hline Ser & $4.5 \pm 0.2$ & $4.7 \pm<0.1$ & $1.6 \pm 0.2$ & $1.2 \pm 0.1$ & $0.3 \pm<0.1$ \\
\hline Glu & $12.0 \pm 0.3$ & $15.2 \pm 0.6$ & $4.4 \pm 0.6$ & $3.5 \pm 0.3$ & $0.9 \pm<0.1$ \\
\hline Pro & $4.3 \pm 0.2$ & $4.6 \pm<0.1$ & $1.6 \pm 0.2$ & $1.3 \pm 0.1$ & $0.6 \pm<0.1$ \\
\hline Gly & $4.7 \pm 0.2$ & $5.1 \pm<0.1$ & $1.8 \pm 0.2$ & $1.4 \pm 0.1$ & $0.4 \pm<0.1$ \\
\hline Ala & $10.8 \pm 0.6$ & $11.0 \pm 0.2$ & $2.6 \pm 0.4$ & $2.2 \pm 0.2$ & $0.5 \pm<0.1$ \\
\hline TPCys & $2.4 \pm 0.5$ & $1.9 \pm 0.1$ & $0.5 \pm<0.1$ & $0.4 \pm 0.1$ & $<0.1$ \\
\hline Val & $5.0 \pm 0.1$ & $5.6 \pm<0.1$ & $1.9 \pm 0.3$ & $1.6 \pm 0.1$ & $<0.1$ \\
\hline Met & $1.9 \pm 0.1$ & $2.2 \pm<0.1$ & $0.8 \pm 0.1$ & $0.7 \pm 0.1$ & $0.1 \pm<0.1$ \\
\hline Ile & $3.7 \pm 0.1$ & $4.1 \pm 0.1$ & $1.4 \pm 0.2$ & $1.1 \pm 0.1$ & $0.3 \pm<0.1$ \\
\hline Leu & $6.2 \pm 0.2$ & $7.4 \pm 0.1$ & $2.5 \pm 0.4$ & $2.1 \pm 0.1$ & $0.6 \pm<0.1$ \\
\hline Tyr & $3.4 \pm 0.2$ & $3.5 \pm 0.1$ & $1.1 \pm 0.2$ & $1.0 \pm 0.1$ & $0.2 \pm<0.1$ \\
\hline Phe & $4.7 \pm 0.1$ & $5.5 \pm 0.1$ & $1.9 \pm 0.3$ & $1.6 \pm 0.2$ & $0.4 \pm<0.1$ \\
\hline His & $2.7 \pm 0.2$ & $1.8 \pm 0.1$ & $0.8 \pm 0.1$ & $0.9 \pm 0.1$ & $0.2 \pm<0.1$ \\
\hline Lys & $5.2 \pm 0.1$ & $5.4 \pm 0.1$ & $1.7 \pm 0.3$ & $1.7 \pm 0.1$ & $0.1 \pm<0.1$ \\
\hline Arg & $4.3 \pm 0.2$ & $4.8 \pm 0.1$ & $1.7 \pm 0.3$ & $1.5 \pm 0.1$ & $<0.1$ \\
\hline
\end{tabular}




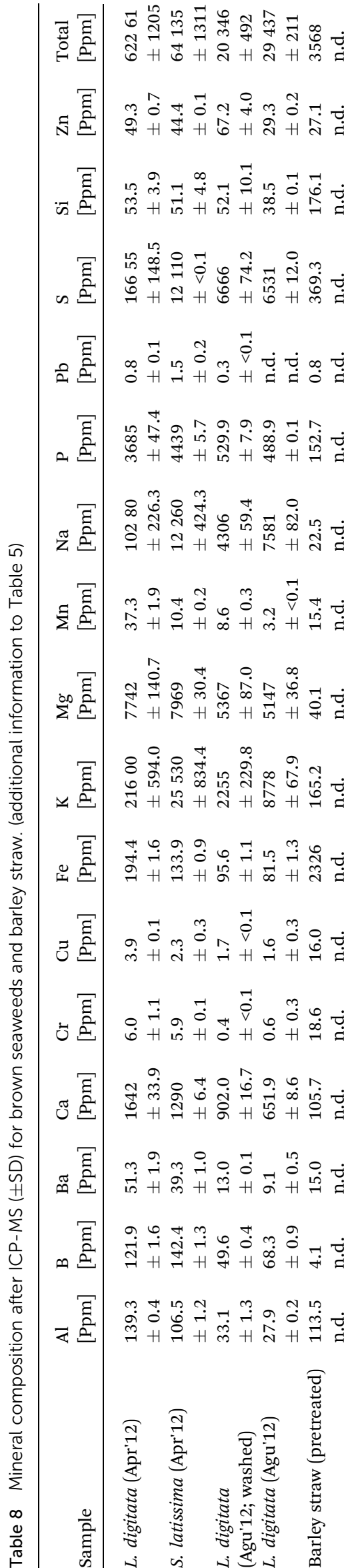

Rasmussen (Aarhus University, Denmark) as well as Ditte B. Toerring and Kristian O. Nielsen (Danish Shellfish Centre, DTUAqua) for providing the seaweeds.

\section{Notes and references}

1 J. M. M. Adams, A. B. Ross, K. Anastasakis, E. M. Hodgson, J. A. Gallagher, J. M. Jones and I. S. Donnison, Bioresour. Technol., 2011, 102, 226-234.

2 D. Ashok, Y. Huang, S. Rezvani, D. McIlveen-Wright, M. Novaes and N. Hewitt, Bioresour. Technol., 2013, 135, 120-127.

3 A. Arnous and A. S. Meyer, Food Bioprod. Process., 2008, 86, 79-86.

4 I. Meseguer, M. Boix, M. C. M. Para and M. V. Aguilar, J. Anal. Chem., 1999, 54, 428-433.

5 S. Willfoer, A. Pranovich, T. Tamminen, J. Puls, C. Laine, A. Suurnakki, B. Saake, K. Uotila, H. Simolin, J. Hemming and B. Holmbom, Ind. Crops Prod., 2009, 29, 571-580.

6 J. Puls, in Biotechnology in Agriculture; Bioconversion of Forest and Agricultural Plant Residues, ed. J. N. Saddler, CAB International, Wallingford, UK, 1993, pp. 13 - 32.

7 A. Sluiter, B. Hames, R. Ruiz, C. Scarlata, J. Sluiter, D. Templeton and D. Crocker, Determination of structural carbohydrates and lignin in biomass, NREL Technical Report July 2011, NREL/TP-510-42618 (Version 0.7.08.2011):1, 2011. 8 W. Black, J. Mar. Biol. Assoc., U.K., 1950, vol. 29, pp. 45-72.

9 E. Percival and R. H. McDowell, in Chemistry and enzymology of marine algal polysaccharides. Academic Press Inc. Ltd., London, 1967.

10 L. E. Rioux, S. L. Turgeon and M. Beaulieu, Phytochemistry, 2010, 71, 1586-1595.

11 A. O. Chizhov, A. Dell, H. R. Morris, A. J. Reason, S. M. Haslam, R. A. McDowell, O. S. Chizhov and A. I. Usov, Carbohydr. Res., 1998, 310, 203-210.

12 S. L. Holdt and S. Kraan, J. Appl. Phycol., 2011, 23, 543597.

13 M. Indegaard, G. Skjåk-Bræk and A. Jensen, Bot. Mar., 1990, 33, 277-288.

14 B. Kloareg and R. S. Quatrano, Mar. Biol., 1988, 26, 259-315. 15 M. T. Ale and A. S. Meyer, RSC Adv., 2013, 3, 8131-8141.

16 M. I. Bilan, A. A. Grachev, A. S. Shashkov, M. Kelly, C. J. Sanderson, N. E. Nifantiev and A. I. Usov, Carbohydr. Res., 2010, 345, 2038-2047.

17 E. D. Obluchinskaya, Appl. Biochem. Microbiol., 2008, 44, 305-309.

18 A. Jensen and A. Haug, Geographical and seasonal variation in the chemical composition of Laminaria hyperborea and Laminaria digitata from the Norwegian coast, Norwegian Institute of Seaweed Research, Report 14, Oslo, 1956, pp. 1-8.

19 M. Indegaard and J. Minsaas, in Seaweed Resources in Europe: Uses and Potential, ed. M. D. Guiry and G. Blunden, John Wiley \& Sons, Chichester, UK, 1991, pp. 21-64.

20 J. Morrissey, S. Kraan and M. D. Guiry, Guide to Commercially Important Seaweeds on the Irish Coast, Bord Iascaigh Mhara/ Irish Sea Fisheries Board, Ireland, 2001. 
21 L. Rosgaard, S. Pedersen and A. S. Meyer, Appl. Biochem. Biotechnol., 2007, 143, 284-296.

22 G. Moxley and Y. H. P. Zhang, Energy Fuels, 2007, 21(6), 3684-3688.

23 S. Horner, J. Puls, B. Saake, E. A. Klohr and H. Thielking, Carbohydr. Polym., 1999, 40, 1-7.

24 M. Sinner, M. H. Simatupang and H. H. Dietrichs, Wood Sci. Technol., 1975, 9, 307-322.

25 T. M. C. C. Filisetti-Cozzi and N. C. Carpita, Anal. Biochem., 1991, 197, 157-162.

26 B. M. v. d. Hoogen, P. R. v. Weeren, M. Lopes-Cardozo, L. M. G. v. Golde, A. Barneveld and C. H. A. v. d. Lest, Anal. Biochem., 1998, 257, 107-111.

27 V. Barkholt and A. L. Jensen, Anal. Biochem., 1989, 177, 318322.

28 S. Willför, J. Hemming and A. Leppänen, Analysis of extractives in different pulps - Method development, evaluation, and recommendations, Laboratory of Wood and Paper Chemistry, Åbo Akademi, Finland, 2006.
29 O. Faix, D. S. Argyropoulos, D. Robert and V. Neirinck, Holzforschung, 1994, 48, 387-394.

30 K. Ostgaard, M. Indegaard, S. Markussen, S. H. Knutsen and A. Jensen, J. Appl. Phycol., 1993, 5, 333-342.

31 A. I. Usov, G. P. Smirnova and N. G. Klochkova, Russ. J. Bioorg. Chem., 2001, 27, 395-399.

32 C. A. Knutson and A. Jeanes, Anal. Biochem., 1968, 24, 482490.

33 A. Ibarz, A. Pagán, F. Tribaldo and J. Pagán, Food Control, 2006, 17, 890-893.

34 L. E. Rioux, S. L. Turgeon and M. Beaulieu, Carbohydr. Polym., 2007, 69, 530-537.

35 S. O. Lourenco, E. Barbarino, J. C. De-Paula, L. O. d. S. Pereira and U. M. Lanfer Marquez, Phycol. Res., 2002, 50, 233-241.

36 P. Ruperez, Food Chem., 2002, 79, 23-26.

37 A. B. Ross, J. M. Jones, M. L. Kubacki and T. Bridgeman, Bioresour. Technol., 2008, 99, 6494-6504. 